\title{
El nuevo panorama en la regulación de los medios audiovisuales y las comunidades autónomas ${ }^{1}$
}

\author{
Mabel López García \\ Departamento de Derecho Público de la UMA
}

\begin{abstract}
SUMARIO²: 1. INTRODUCCIÓN. 2. EL MARCO JURÍDICO GENERAL DE PARTIDA. 2.1. El plano técnico o del soporte. 2.2. El plano de la comunicación social. 3. LAS COMUNIDADES AUTÓNOMAS Y LA EVOLUCIÓN DE SU MARCO COMPETENCIAL EN MATERIA DE RADIO Y TELEVISIÓN. 3.1. Los Estatutos de Autonomía originarios y la Constitución española. 3.2. El condicionante de las competencias autonómicas por el Estatuto de Radio y Televisión de 1980. 3.3. Reconocimiento progresivo de mayores competencias a las Comunidades Autónomas. 3.4. La cuestión de fondo. 4. EL HORIZONTE INMEDIATO DE LA REGULACIÓN AUDIOVISUAL Y LAS COMUNIDADES AUTÓNOMAS. 4.1. La proyectada reforma general del sector audiovisual. 4.2. Limitada, hasta hoy, puesta en práctica de la reforma: La Ley de Radio y Televisión de Titularidad Estatal y su significado para las Comunidades Autónomas. 4.3. Previsiones establecidas en las nuevas reformas estatutarias. 5. CONCLUSIONES.
\end{abstract}

\section{INTRODUCGIÓN}

La regulación de los medios audiovisuales ofrece hoy por hoy en España, un entramado legislativo compuesto por un conjunto profuso y asistemático de normas y necesitado, por tanto, de la oportuna sistematización.

\footnotetext{
${ }^{1} \mathrm{El}$ presente trabajo tiene como origen una comunicación presentada en las XIII Jornadas de Jóvenes Investigadores en Comunicación, celebrada en Zaragoza los días 26 y 27 de octubre de 2006.

${ }^{2}$ Abreviaturas: art.: Artículo; d.a.: disposición adicional; d.d.u.: disposición derogatoria única; d.t.: disposición transitoria; CE: Constitución Española; BOCG: Boletín Oficial de las Cortes Generales; BOE: Boletín Oficial del Estado; f.j.: fundamento jurídico; ERTV: Ley 4/1980, de 10 de enero, Estatuto de Radio y Televisión; LOTel: Ley 31/1987, de 18 de diciembre, de Ordenación de las Telecomunicaciones; LTP: Ley 10/1988, de 3 de mayo, de Televisión Privada; LTC: Ley
} 
Ese entramado es producto de una progresiva evolución legislativa en la que, tras la promulgación de la Constitución de 1978, al Estatuto de Radio y Televisión de 1980 (ERTV) ${ }^{3}$, norma básica y referencial del audiovisual, se fueron superponiendo muchas otras normas específicas para permitir la explotación de la radio y la televisión por sujetos distintos del Estado, así como la apertura del sector a las nuevas modalidades tecnológicas.

Pues bien, un dato característico de dicha evolución ha sido el progresivo protagonismo asumido por las Comunidades Autónomas, como reguladoras y responsables de la provisión de servicios de radio y televisión. En efecto, declarada la radio y la televisión por el ERTV, en principio, como un servicio público de titularidad estatal -cuya gestión indirecta por entes privados sólo tuvo lugar a partir de 1988 con la Ley de Televisión Privada (LTP)-, las Comunidades Autónomas no tardaron en asumir la gestión del llamado "tercer canal" de televisión en virtud de concesión estatal, asumiendo también posteriormente, nuevas competencias sobre radio en frecuencia modulada y televisión digital terrestre. A ello se añade el importante punto de inflexión que supone la reforma del sector audiovisual proyectada por el Gobierno de la Nación en 2005 y que ha comenzado ya a hacerse realidad, así como el proceso de reforma de los Estatutos de Autonomía actualmente en curso.

En el presente trabajo vamos a sintetizar el ámbito actual de las competencias reguladoras y de prestación de servicios audiovisuales por las Comunidades Autónomas, y realizar un esbozo del nuevo horizonte de la descentralización autonómica en el campo de los medios audiovisuales.

46/1993, de 26 de diciembre, reguladora del Tercer Canal de Televisión; LTelS: Ley 37/1995, de 12 de diciembre, de Telecomunicaciones por Satélite; LTelC: Ley 42/1995, de 22 de diciembre, de Telecomunicaciones por Cable; LTLOT: Ley 41/1995, de 22 de diciembre, por la que se reguló la Televisión Local por Ondas Terrestres; LMFAOS 66/1997: Ley 66/1997, de 30 de diciembre, de Medidas Fiscales Administrativas y del Orden Social; LGTel 11/1998: Ley 11/1998, de 24 de abril, General de las Telecomunicaciones; LGTel 32/2003: Ley 32/2003, de 3 de noviembre, General de las Telecomunicaciones; LRTVTE: Ley 17/2006, de 5 de junio, de la Radio y Televisión de titularidad estatal; núm.: número; RTVE: Radio Televisión Española; RNE: Radio Nacional de España; TVE: Televisión Española; TC: Tribunal Constitucional; STC: Sentencia del Tribunal Constitucional; SSTC: Sentencias del Tribunal Constitucional.

${ }^{3}$ La Ley 4/1980, de 10 de enero, de Estatuto de Radio y Televisión, ha estado vigente hasta su derogación por la Ley de Radio y Televisión de titularidad estatal de 2006. No obstante, queda subsistente a efectos de la Ley del Tercer Canal de Televisión y la Ley de Televisión Privada, como veremos. 


\section{EL MARCO JURÍDICO GENERAL DE PARTIDA ${ }^{4}$}

En el ámbito de los medios audiovisuales confluyen dos planos: el plano técnico o del soporte (telecomunicaciones) y el estricto plano de la comunicación social ${ }^{5}$. La primera materia, como régimen general de las comunicaciones, telecomunicaciones y radiocomunicación es competencia exclusiva del Estado (149.1.21 CE). La segunda, en cambio, como régimen general de los medios de comunicación social es competencia compartida del Estado y las Comunidades Autónomas (149.1.27), las cuales en virtud de la correlación bases-desarrollo que éste último precepto consagra, podrán ejercer sobre el sector y en el ámbito de sus competencias, potestades tanto de ordenación como de desarrollo de la actividad audiovisual.

\subsection{El plano técnico o del soporte}

La regulación de las telecomunicaciones -por referirnos a los antecedentes más inmediatos- se llevó a cabo por la Ley 31/1987, de 18 de diciembre, de Ordenación de las Telecomunicaciones (LOTel), la cual configuró las telecomunicaciones como un servicio público de titularidad estatal, objeto de prestación directa por el sector público o en su caso indirecta concesional por entidades privadas. De esta manera, las diversas modalidades técnicas de transmisión de la comunicación audiovisual (transporte de señal radioeléctrica, cable, satélite, etc.) eran en sí mismas un servicio público que requería concesión. Todo ello al margen de que la propia actividad de comunicación social (explotación de la radio, la televisión, etc.), configurada asimismo y en cuanto tal como servicio público, requiriese concesión si no era prestada por el Estado (por RTVE).

Pero la LOTel (y con ella su fundamental previsión: la "publicatio" de las telecomunicaciones) será posteriormente derogada en el proceso de "liberalización" de las telecomunicaciones. Como primer paso en ese proceso, la ruptura del monopolio estatal de los servicios técnicos, soporte de la comunicación social, se produjo en $1995^{6}$ al quedar liberalizadas las telecomunicacio-

\footnotetext{
${ }^{4}$ Véase CARLÓN RUIZ, M. (2000): "Régimen de la telecomunicaciones. Una perspectiva convergente en el Estado de las Autonomías”, Madrid, La Ley. SOUVIRÓN MORENILLA, J.M. (1999): Derecho público de los medios audiovisuales radiodifusión y televisión, Granada, Comares.

${ }^{5} \mathrm{Al}$ referirnos a la división técnica-social, lo hacemos siguiendo una lógica conceptual y real, pero no estrictamente legislativa, como podremos comprobar.

${ }^{6}$ Con la Ley 37/1995, de 12 de diciembre, de Telecomunicaciones por Satélite.
} 
nes por satélite como consecuencia del derecho comunitario ${ }^{7}$ (para prestar dicho servicio técnico sería necesario obtener una autorización y ya no una concesión). Esta medida tomada para un ámbito sectorial fue luego generalizada: primero por la Ley 11/1998, de 24 de abril, General de Telecomunicaciones (LGTel 11/1998), que derogó a la $\mathrm{LOTel}^{8}$, y finalmente por la vigente Ley 32/2003, General de Telecomunicaciones (LGTel 32/2003), con la que se entra en un régimen de libertad y libre competencia para la prestación de los servicios de telecomunicaciones, incluidos los soportes de los medios audiovisuales. Y ello, porque la LGTel 2003 otorga a ese respecto una habilitación general e inmediata para dicha prestación con el único requisito de su previa notificación a la Comisión del Mercado de las Telecomunicaciones (lo que no excluye que si a tal fin se utiliza el espectro radioeléctrico deba obtenerse el correspondiente título demanial administrativo).

\subsection{El plano de la comunicación social}

En el plano de la comunicación social, como hemos dicho, la regulación del sector se realizó, tras la Constitución española, a través del ERTV, en el que se define la radio y la televisión como un servicio público esencial cuya titularidad corresponde al Estado ${ }^{9}$. Esto tendrá dos consecuencias importantes: primera, la imposibilidad de la explotación privada de medios audiovisuales salvo que se obtenga la necesaria concesión administrativa de dicho servicio público $^{10}$, (posibilidad hecha efectiva para la televisión con la Ley 10/1988, de

\footnotetext{
${ }^{7}$ Concretamente por las modificaciones producidas en la normativa comunitaria como consecuencia de la aprobación de la Directiva 94/64/CEE, de 31 de octubre de 1994, por la que se modifican las Directivas 88/301/CEE, de 16 de mayo de 1988, relativa a la competencia de los mercados de terminales de telecomunicaciones y 90/388/CEE, de 28 de junio de 1990, relativa a la competencia en los mercados de servicios de telecomunicaciones.

${ }^{8}$ Sin embargo, quedan vigentes aún los preceptos de la LOT 31/1987 por los que se establecen el régimen aplicable a los servicios de radiodifusión y televisión en el marco de la comunicación social. Véase la d.d.ú. b) de la LGTel 32/2003 y d.t. 6ª de la LGTel 11/1998.

${ }^{9}$ Art. 1 del ERTV.

${ }^{10}$ Respecto a la posibilidad de creación de medios de comunicación privados se ha pronunciado el Tribunal Constitucional en diversas sentencias, reconociendo la existencia de la televisión privada como una opción del legislador (SSTC 12/1982, 74/1982, 79/1982; 106/1986; 88/1995, entre otras).
} 
televisión privada [LTVP $]^{11}$ ); y segunda, el que también la explotación de la radio y la televisión por las Comunidades Autónomas quedara sujeta a ese mismo requisito concesional a su favor (lo que hizo efectivo como luego veremos la Ley del Tercer Canal).

Estas previsiones del ERTV fueron concretadas posteriormente por la LOTel que en sus preceptos relativos a la comunicación social ${ }^{12}$-únicos vigentes aún, una vez que la LOTel fue derogada por la LGTel 2003-, estableció la "publicatio" de los servicios de radiodifusión sonora y televisión en cuanto tales y al margen del régimen aplicable a los servicios de telecomunicaciones, soporte de los citados servicios de difusión, en los siguientes términos. La televisión por ondas terrestres se configura como un servicio público a prestar en régimen de gestión directa por el Estado o sus Entes Públicos, o en régimen de gestión indirecta mediante concesión administrativa estatal a través de personas físicas o jurídicas. En el ámbito de la radiodifusión, las competencias sobre el servicio para la explotación de la onda corta y larga están atribuidas exclusivamente al Estado o sus entes públicos; en onda media la explotación se podrá realizar mediante la gestión directa por el Estado o sus Entes Públicos y mediante la gestión indirecta previo otorgamiento de concesión a personas físicas o jurídicas; y en la banda de frecuencia modulada, la LOTel contempla una gestión directa compartida entre Estado y las Comunidades Autónomas, y una gestión indirecta (concesional) por los entes locales y los particulares otorgada asimismo en términos compartidos entre el Estado y las Comunidades Autónomas.

\footnotetext{
${ }^{11}$ Cuya novedad fue la de posibilitar la creación en cobertura estatal de nuevos canales de televisión gestionados por sociedades anónimas en régimen de concesión administrativa, que permitiría el pluralismo de los medios de comunicación, pero sin alejarse del designio publificante mantenido por el ERTV, dado que lo que regula la Ley es la gestión indirecta del servicio público esencial de televisión previa concesión, como ya se hizo para la radio por la LOTel. Actualmente tienen concesión para la gestión indirecta Antena 3 de Televisión, S.A.; Sogecable, S.A. y Gestevisión Telecinco, S.A. (Resolución de 10 de marzo de 2000, de la Secretaría General de Comunicaciones, BOE núm. 61 de 11 de marzo de 2000); Veo Televisión, S.A. y Sociedad Gestora de Televisión Net TV, S.A (Resolución de 13 de diciembre de 2000, de la Secretaría de Estado de Telecomunicaciones y para la Sociedad de la Información, BOE núm. 8, de 9 de enero de 2001) y la sociedad Gestora de Inversiones Audiovisuales La Sexta, S.A. (Resolución de 30 de noviembre de 2005, de la Secretaría de Estado de Telecomunicaciones y para la Sociedad de la Información, BOE núm. 301, de 17 de diciembre de 2005).
}

${ }^{12}$ Artículos 25, 26, 36 y d.d. $6^{\mathrm{a}}$ de la LOTel. 
Pero el plano de la comunicación social no queda configurado exclusivamente por el esquema expuesto, sino que una serie de normas sectoriales vinieron a complementar las previsiones del ERTV y la LOTel.: la Ley 41/1995, de 22 de diciembre, por la que se reguló la Televisión Local por Ondas Terrestres (LTLOT), la Ley 42/1995, de 22 de diciembre, de Telecomunicaciones por Cable (LTelC), la Ley 37/1995, de 12 de diciembre, de Telecomunicaciones por Satélite (LTelS), la Ley 66/1997, de 30 de diciembre, de Medidas Fiscales, Administrativas y del Orden Social (LMFAOS 66/1997), que regulan los servicios públicos de radiodifusión sonora y de televisión digital terrenal. Todas estas normas, salvo en el supuesto de la LTelS, anteriormente referida, mantenían la necesidad de concesión para la prestación del servicio público de radio y televisión, partiendo del criterio consagrado por el ERTV.

Todo ello, sin perjuicio de la Ley 46/1993, de 3 de diciembre del Tercer Canal (LTC), y las previsiones de las anteriores normas -modificadas en su mayoría-, referentes a las Comunidades Autónomas, cuestión que ahora abordaremos.

\section{LAS COMUNIDADES AUTÓNOMAS Y LA EVOLUCIÓN DE SU MARCO COMPETENCIAL EN MATERIA DE RADIO Y TELEVI- SIÓN}

Como hemos visto, el ERTV de 1980, norma de cabecera de todo el sector, consagró un modelo de servicio público de radiotelevisión basado en la absoluta titularidad estatal de la radio y televisión. Eso sí, con la posibilidad de que las Comunidades Autónomas gestionaran directamente un canal de televisión -repárese- de titularidad estatal, para el ámbito territorial de cada Comunidad Autónoma ("tercer canal de televisión" regulado por la Ley 46/1993, de 3 de diciembre [LTC]).

Esta configuración por el ERTV de la radiotelevisión como un servicio público de titularidad estatal planteaba una serie de problemas respecto a su constitucionalidad, en cuanto que aquélla podía exceder de la competencia del legislador estatal derivada del artículo 149.1.27, además de entrar así en conflicto con situaciones jurídicas con base constitucional, previas a la aprobación del ERTV, y mediatizar el contenido competencial de las Comunidades Autónomas sobre sus propios servicios de radiotelevisión. Sin embargo, como veremos, el propio devenir de los hechos resolvió en la práctica la situación. 


\subsection{Los Estatutos de Autonomía originarios y la Constitución Española}

Cataluña y el País Vasco, que accedieron a la autonomía por la vía rápida asumieron en sus Estatutos, aprobados en 1979, las competencias que en materia de medios de comunicación les otorga la Constitución conforme al reparto bases-desarrollo ${ }^{13}$ (reparto que, en principio, permitía la titularidad de las Comunidades Autónomas sobre unos propios servicios de radiotelevisión, pero que, sin embargo, el ERTV vendría a impedir conforme a lo expuesto).

En el Estatuto de Cataluña, la asunción de las competencias (regulación y creación de medios propios) se hizo con expresa supeditación a lo que dispusiera la legislación básica (ERTV) y con la identificación de su televisión con la de un tercer canal de titularidad estatal concedido a la Comunidad Autónoma. En cambio, el Estatuto de Autonomía vasco efectúa la atribución directamente, desvinculada de la necesidad del título habilitante que proclama el ERTV. De este modo la Comunidad Vasca explotaría su televisión no como concesionaria sino como titular del servicio, además de la posibilidad de disponer en concesión para su ámbito territorial de un tercer canal de titularidad estatal. La fórmula competencial utilizada por los Estatutos del resto de las Comunidades Autónomas que accedieron a la autonomía por la vía rápida (Galicia y Andalucía), siguió el esquema del Estatuto catalán, supeditando su competencia en la materia a lo dispuesto por la normativa estatal y precisando la obligación por parte del Estado de otorgar la gestión del tercer canal de televisión a la Comunidad Autónoma en el ámbito territorial que le es propio. Por su parte, las Comunidades que accedieron a la autonomía por la vía lenta, asumieron las competencias derivadas del artículo 149.1.27 de la Constitución en términos dispares para dar así el siguiente cuadro:

El modelo del País Vasco, con competencia propia en la materia; las Comunidades de Cataluña, Galicia y Andalucía, al igual que, bajo otras fórmulas, Valencia, Canarias y Navarra cuyos Estatutos sometían su competencia a la regulación estatal básica y a la concesión de la gestión de un tercer canal de televisión de titularidad estatal para su ámbito territorial; y el modelo de Asturias, Cantabria, La Rioja, Murcia, Aragón, Castilla-León, Extremadura, Las Islas Baleares, Madrid y Castilla la Mancha que no asumieron las competencias en esta materia hasta 1992, en virtud de la Ley Orgánica 9/1992, de 23 de diciembre, de transferencia de competencias a las Comunidades Autónomas

13 149.1.27 CE. 
que accedieron a la autonomía por la vía lenta y las anteriores reformas de sus Estatutos.

\subsection{El condicionante de las competencias autonómicas por el Estatuto de Ra- dio y Televisión de 1980 .}

La supeditación de las competencias estatutarias de las Comunidades Autónomas -salvo en el caso del País Vasco- a lo que estableciera el ERTV tenía consecuencias relevantes:

En primer lugar en cuanto al fondo, porque en el sector de la radio, y aunque el ERTV no acotaba los términos y casos en los que las hipotéticas competencias de las Comunidades Autónomas debían ser ejercidas para la difusión por este medio, la titularidad estatal sobre este servicio público, que dicho ERTV consagraba, venía a dejar al margen tal hipótesis y porque en el caso de la televisión la "autolimitación estatutaria"14 había reducido la competencia autonómica a la gestión en concesión de un tercer canal estatal. Concesión que actualmente tienen otorgada País Vasco (1984), Cataluña (1984), Galicia (1985), Andalucía (1988), Comunidad Valenciana (1988), Madrid (1988), Canarias (1988), Castilla-La Mancha (2001), Baleares (2004), Extremadura (2004), Asturias (2004), Aragón (2004) y Murcia (2005).

En segundo lugar, y en cuanto a la forma, tanto el ERTV como la LTC obligaban a que los servicios de radiotelevisión de las Comunidades Autónomas se ajustasen orgánica y funcionalmente a los criterios establecidos para el Ente Público Estatal Radio y Televisión Española y sus sociedades ${ }^{15}$ (consejo de administración, consejos asesores y director general).

\subsection{Reconocimiento progresivo de mayores competencias a las Comunidades Autónomas}

No hay duda de que esta rigidez en el reconocimiento de competencias radiotelevisivas a las Comunidades Autónomas, fundada en las previsiones del ERTV, chocaba con las hipótesis abiertas por el art. 149.1.27 de la Constitución. De ahí que primero por la jurisprudencia constitucional -en materia de

\footnotetext{
${ }^{14}$ Expresión utilizada por SOUVIRÓN MORENILLA, J.M. (1999): Derecho público de los medios audiovisuales radiodifusión y televisión, Granada, Comares, p. 87.

15 Radio Nacional de España (RNE) y Televisión Española (TVE).
} 
radio- y luego por las normas específicas sucesivamente superpuestas al ERTV, progresivamente se fueron aumentando las competencias de las Comunidades Autónomas. Así, la LOTel en el ámbito de la radio analógica, según ya hemos visto, y en el de la televisión una serie de normas a las que hacemos referencia sucinta:

La Ley 25/1994, modificada en 1999, sobre actividades de radiodifusión televisiva reconoce tanto al Estado como a las Comunidades Autónomas, competencia de control e inspección respecto a la programación del tercer canal de televisión, y de los servicios de televisión sobre los que corresponda a las Comunidades Autónomas otorgar el título habilitante.

La LTLOT de 1995, omitió toda referencia a la titularidad y atribuyó a las Comunidades Autónomas la competencia para determinar el número de concesiones de televisión local ${ }^{16}$, adjudicarlas y desarrollar la Ley dentro de sus competencias, incluido el régimen sancionador. Aunque el desarrollo normativo no tuvo lugar, por lo que no pudo llevarse a cabo el proceso de concesión, (que se ha iniciado ahora tras la modificación sufrida en los últimos años en el marco normativo originario ${ }^{17}$, conforme a la cual la televisión local se reconfigura como digital) las Comunidades Autónomas mantienen la competencia para otorgar la concesión.

Igualmente la LTelC con su Reglamento ${ }^{18}$, hoy derogada parcialmente por la LGTel 32/2003, otorgó a las Comunidades Autónomas diferentes competencias, entre otras: aprobar las demarcaciones territoriales que superasen un término municipal y las correspondientes potestades de inspección y sancionadoras. Tras la entrada en vigor de la LGTel 32/2003 los servicios de ra-

\footnotetext{
${ }^{16}$ Conforme al ERTV y la normativa originaria, los entes locales no gozan de competencia alguna en el ámbito del sector audiovisual, lo cual no fue obstáculo para evitar la aparición de éstas tanto por iniciativa privada como pública. La situación llevó a varios pronunciamientos del Tribunal Constitucional al respecto, el cual negó la ilegalidad de las emisoras y reclamó al legislador la regulación de estas modalidades televisivas. Véase: ROZADOS OLIVA, M.J. (2001): "La regulación de las televisiones locales por ondas en Andalucía”. Revista de Estudios de la Administración local, no 286-287, mayo-diciembre.

17 Véase la Ley de Medidas Fiscales Administrativas y del Orden Social 53/2002 y 62/2003 y la Ley 10/2005, de 14 de junio, de Medidas Urgentes para el Impulso de la Televisión Digital Terrestre, de Liberalización de la Televisión por Cable y Fomento del Pluralismo.

${ }^{18}$ Real Decreto 2066/1996, de 13 de septiembre.
} 
dio y televisión por cable han quedado liberalizados, y sujetos sólo a una autorización administrativa, que corresponde otorgar a las Comunidades Autónomas.

Posteriormente, la Ley 66/1997 de Medidas Fiscales Administrativas y del Orden Social (LMFAOS 66/1997), al regular en su disposición adicional $44^{19}$ los servicios públicos de radiodifusión sonora y de televisión digital terrenal, lo que hace sin pronunciarse sobre el titular de tales servicios públicos, determina rotundamente que las concesiones para su gestión indirecta se otorgará por el Estado si su ámbito es estatal y por la Comunidad Autónoma si es autonómico o local.

\subsection{La cuestión de fondo}

La cuestión de fondo que subyace bajo todo el entramado legislativo analizado es si las Comunidades Autónomas tienen competencia propia en materia de radio y televisión. A lo que debemos contestar: sí, tanto de desarrollo como de ejecución (respetando la normativa estatal básica) conforme a la Constitución (art. 149.1.27) y, en principio, a sus Estatutos de Autonomía. Lo que, sin embargo, sucede es que los originarios Estatutos de Autonomía se autolimitaron por lo que dijera el ERTV, el cual, junto con la LTC "estatificó" toda la actividad tras declararla servicio público, sin posibilidad de que las Comunidades Autónomas tuvieran competencias propias en la materia.

Ya hemos precisado que ese estricto resultado se ha ido matizando progresivamente por la legislación sectorial, configurándose de este modo un bloque normativo confuso sobre el que ciertamente se intentó poner orden con un Proyecto de Ley reguladora del Servicio Público de Televisión Autonómi$\mathrm{ca}^{20}$, que, sin embargo, no llegó a aprobarse como consecuencia de la caduci-

\footnotetext{
${ }^{19}$ Modificada por la Ley 55/1999, de 29 de diciembre, de Medidas Fiscales, Administrativas y del Orden Social.

${ }^{20} \mathrm{El}$ proyecto establecía la titularidad por parte de las Comunidades Autónomas del servicio público de televisión autonómica, precisando las competencias de éstas para su organización, dirección y gestión, pudiendo optar entre la doble modalidad gestora (directa o indirecta), o por ambas; así como la posibilidad de regular su organización sin condicionante alguno, como los que hasta ahora habían mantenido el ERTV y la LTC. BOCG. Congreso de los Diputados, serie A, núm. 98.1, de 30 de diciembre de 1997.
} 
dad $^{21}$ de la iniciativa por disolución de las Cortes Generales ${ }^{22}$, manteniéndose por ello el mismo esquema hasta ahora expuesto. En cualquier caso, la evolución legislativa en la materia ha tendido hacía una apertura competencial por la cual el Estado se aleja cada vez más de su monopolio histórico sobre el sector, y que halló su principal y última expresión, -en lo que respecta al reconocimiento de competencias a las Comunidades Autónomasen la LMFAOS 66/1997 que, en efecto, atribuye competencia a las Comunidades autónomas en su respectivo ámbito, en materia de radio y televisión digital.

Pero la problemática siguió latente y ha venido a complicarse aún más tras las recientes disposiciones de algunas Comunidades Autónomas. Nos referimos a las reformas de los Estatutos de Autonomía de Valencia, Cataluña y Andalucía, en las que más adelante nos detendremos. Aunque ya con anterioridad Cataluña, a través de su Ley de comunicación audiovisual ${ }^{23}$ y Valencia, mediante su Ley del sector audiovisual ${ }^{24}$; ampliaron sus competencias en la materia.

\section{EL HORIZONTE INMEDIATO DE LA REGULACIÓN AUDIOVI- SUAL Y LAS COMUNIDADES AUTÓNOMAS}

El sector audiovisual en España, como hemos podido comprobar, ha estado regido hasta el momento por un bloque normativo hecho de normas fragmentarias aprobadas al paso del avance de la técnica y en paralelo al proceso de liberalización de las telecomunicaciones, lo que hace que cualquiera que pretenda acercarse a esta materia se encuentre en primer lugar desconcertado y posteriormente asombrado de tan deficiente regulación, en la que cada norma complementa y completa a la anterior.

\footnotetext{
21 Caducidad probablemente provocada dado que chocaba con el impulso de la televisión digital terrestre que era lo que políticamente interesaba.

${ }^{22}$ BOCG. Congreso de los Diputados, serie D, núm. 543, de 4 de febrero de 2000.

${ }^{23}$ Ley 22/2005, de 29 de diciembre, de la Comunicación Audiovisual de Cataluña.

${ }^{24}$ Ley 1/2006, de 19 de abril, del Audiovisual de Valencia.
} 


\subsection{La proyectada reforma general del sector audiovisual}

Esta situación llevó en 2005 al Gobierno de la Nación a hacer público un plan de reforma global del sector audiovisual que ya se ha empezado a poner en práctica. El plan, acorde con los principios de neutralidad tecnológica, liberalización de la prestación, obligaciones de servicio público, pluralismo y derechos de los ciudadanos; incluye la aprobación de una Ley General Audiovisual, una Ley de Creación del Consejo Estatal de los Medios Audiovisuales ${ }^{25}$, una Ley del Servicio Público de Radio y Televisión de titularidad Estatal ${ }^{26}$, así como dos Reales Decretos de modificación del Plan Técnico Nacional de Televisión Digital ${ }^{27}$ y del Plan Técnico Nacional de la Televisión Privada ${ }^{28}$.

Pero motivos más cercanos a la lógica política que a la jurídica parecen estar retrasando esta reforma. En efecto, el plan de reforma, tenía en su origen una lógica sistemática perfectamente coherente con el bloque de la constitucionalidad y el esquema de los artículos 149.1.21 y 149.1.27 de la Constitución, eje central de todo el entramado normativo. Pero esta lógica se ha visto un tanto frustrada dado el desorden en la aprobación de los citados proyectos normativos.

La Ley General Audiovisual, en estos momentos aún en fase de borrador, constituiría la norma básica en la materia de acuerdo con el art. 149.1.27 de la $\mathrm{CE}$, y en su virtud quedaría liberalizado el sector, que dejaría de ser en su totalidad un servicio público (servicio público subjetivo) para constituirse como un servicio liberalizado, aunque regulado y a prestar en libre competencia. En principio, pues, cualquier persona física o jurídica, con nacionalidad o domicilio social en un Estado miembro de la Unión Europea, podría prestar el servicio de difusión de radio o televisión tan sólo con la previa notificación a la Administración competente, salvo en el supuesto de que se preste el servicio

${ }^{25}$ Ambas aún en fase de borrador, disponibles en http:// fes.ugt.org/RTVE/portada.htm

${ }^{26}$ Ley 17/2006, de 5 de junio, de la Radio y Televisión de Titularidad Estatal.

${ }^{27}$ Real Decreto 944/2005, de 29 de julio, por el que se aprueba el Plan Técnico Nacional de la Televisión Digital Terrestre y el Real Decreto 945/2005, de 29 de julio, por el que se aprueba el Reglamento General de Prestación del Servicio de Televisión Digital.

${ }^{28}$ Real Decreto 946/2005, de 29 de julio, por el que se aprueba la incorporación de un nuevo canal analógico de televisión en el Plan Técnico Nacional de Televisión Privada, aprobado por el Real Decreto 1362/1988, de 11 de noviembre. 
por ondas hertzianas en cuyo caso será necesario disponer de licencia -repárese ya no concesión- que otorgará el Estado o las Comunidades Autónomas según el ámbito de la prestación (nacional o autonómico). Únicamente, se considerarán servicios públicos de radio y televisión (servicio público objetivo) los servicios de difusión por ondas hertzianas que preste el sector público (estatal, autonómico o local), lógicamente en paralelo a los que preste el sector privado bajo el régimen citado; aunque a estos últimos servicios de difusión de radio y televisión, independientemente de la técnica utilizada para la difusión de sus contenidos, pueden imponérseles obligaciones de servicio público al objeto de proteger el pluralismo y los derechos de los ciudadanos.

Acorde con lo anterior y dada la proyectada liberalización del sector que consagraría la Ley General Audiovisual, surge la necesidad de una Ley del Servicio Público de Radio y Televisión de Titularidad Estatal (es decir de la radio y televisión del sector público estatal), la única ley de las proyectadas en la reforma efectivamente aprobada por el momento (Ley 17/2006, de 5 de junio), que deroga en parte el ERTV, pero no adquiere el carácter de norma básica que éste tenía dado que la norma básica sería la proyectada Ley General Audiovisual, aún no aprobada.

El plan de reforma proyectado se completa con la Ley de Creación del Consejo Estatal de los Medios Audiovisuales, por la que se creará un organismo administrativo independiente que en el marco de las competencias directas del Estado vele por el respeto de los derechos y libertades en el ámbito de los medios de comunicación, y que se supone garantizará el mantenimiento del pluralismo, de la transparencia en los medios, de los derechos de los ciudadanos y los intereses socioculturales, garantizando que en la programación de radio y televisión se respeten los principios constitucionales y la legislación vigente para la protección de los telespectadores y radioyentes. Configurándose de este modo, una administración independiente cuyas decisiones ponen fin a la vía administrativa aunque con la eficacia de un laudo arbitral sometido a la Ley 60/2003, de 23 de diciembre, de Arbitraje.

\subsection{Limitada, hasta hoy, puesta en práctica de la reforma: la Ley de Radio y Televisión de Titularidad Estatal y su significado para las Comunidades Autó- nomas.}

La Ley 17/2006 de Radio y Televisión de Titularidad Estatal (LRTVTE), supone el segundo cambio real hecho efectivo entre las medidas de reforma del sector audiovisual iniciadas por el Gobierno. El primer cambio se dio con la modificación del Plan Técnico Nacional de Televisión Digital Terrestre y 
del Plan Técnico Nacional de Televisión Privada. En virtud de esta última se amplió a la emisión en abierto la concesión de televisión privada hecha a Sogecable (Canal+ que ha pasado a ser el canal Cuatro), y se otorgó la concesión de un nuevo canal analógico: la Sexta. Y aún, quedan por aprobar la Ley General Audiovisual y la Ley de Creación del Consejo Estatal de los Medios Audiovisuales, todavía en fase de borrador; las cuales, en nuestra opinión, deberían haber sido el primer cambio real llevado a cabo, dado que todas las modificaciones producidas en este ámbito se han realizado conforme a un criterio conjunto en el que la Ley General Audiovisual constituye la base para su expresión normativa.

Centrándonos, pues, en esta LRTVTE ya aprobada, queda transformado el régimen de la radio televisión pública estatal (Ente Público RTVE, regulado hasta ahora por el ERTV 1980), que será gestionado por un nuevo ente: la Corporación de la Radio y la Televisión Española, S.A., y bajo las nuevas claves de su funcionamiento como servicio público objetivo, en las que ahora no podemos detenernos. Pero en lo que nos interesa, conviene precisar que aunque la nueva LRTVTE ha derogado expresamente el ERTV de 1980, lo mantiene vigente en cuanto a la televisión hoy explotada al amparo de la LTC y la LTP. ¿Qué quiere decir esto?, pues que todo el régimen aplicable a la radiotelevisión gestionada por el Estado será ya el de la nueva LRTVTE y no el previsto por el ERTV, que por eso y a tal efecto se deroga, aunque, en cambio, el régimen hasta hoy aplicable a la televisión privada (LTP) y la televisión de cobertura autonómica (en esencia la LTC) se mantiene vigente, incluso en los aspectos que directa o subsidiariamente estaban regidos por el ERTV de 1980, que por eso y sólo respecto de estos dos últimos ámbitos queda subsistente, ciertamente hasta que tengan lugar otros cambios normativos que ahora referiremos.

En definitiva, al menos transitoriamente, las Comunidades Autónomas seguirán siendo concesionarias de la gestión directa de un tercer canal de televisión de titularidad estatal, siendo este título el habilitante y condicionante de la gestión de la radio y televisión autonómica por los respectivos organismos públicos de Radiotelevisión de las Comunidades Autónomas.

En cambio, una vez se apruebe la Ley General Audiovisual proyectada se producirá la liberalización de la radio y la televisión, consecuencia del paso del servicio público subjetivo al servicio público objetivo, y con ello la explotación de la radio y la televisión por las Comunidades Autónomas no estará sujeta ya al ERTV y su alcance sino a la Ley General Audiovisual, que cuando se apruebe será la norma básica. Entonces, y conforme a ella las Comunidades Autónomas tendrán libertad para regular la radio y la televisión de su titularidad y 
competencia, ciertamente en el marco de lo previsto para la radiotelevisión de explotación pública como servicio público objetivo. Sin embargo, como hemos dicho, la Ley General Audiovisual no se ha aprobado, y por ello se mantiene la vigencia parcial del ERTV, constituyendo la recién aprobada LRTVTE, sólo una norma reguladora del servicio estatal de radio y televisión de difusión territorial estatal e internacional, sin efecto alguno sobre la regulación y difusión autonómicas.

Por lo demás la emisión digital y la conversión de la emisión analógica a la digital en cobertura autonómica, seguirá también regida conforme a la legislación vigente: el actual Reglamento general de prestación del servicio de televisión digital terrestre ${ }^{29}$, que prevé que éste se gestione en régimen de gestión directa ajustándose a lo establecido en el ERTV y en la LTC, y en su gestión indirecta por particulares, en virtud de concesión de la Comunidad Autónoma. Todo ello hasta que se apruebe la legislación que lo sustituya (en su momento la Ley General Audiovisual).

\subsection{Previsiones establecidas en las nuevas reformas estatutarias}

Si atendemos a las reformas de los Estatutos de Autonomía recientemente realizadas (Valencia ${ }^{30}$ Cataluña ${ }^{31}$,y Andalucía ${ }^{32}$ ) podemos comprobar como la descentralización autonómica de los medios de comunicación ha encontrado un definitivo punto de inflexión. Así por ejemplo, tanto el nuevo Estatuto de Cataluña como el de Andalucía, incluyen sus propios conceptos de competencia exclusiva, compartida y ejecutiva, reduciendo a meros principios o mínimo común, el contenido de la normativa básica que fije el Estado, excepto en los supuestos que se determinen de acuerdo con la Constitución y los nuevos Estatutos. Esto chocaría frontalmente, en lo que aquí nos afecta, con la Ley General Audiovisual, norma básica del sector en proyecto, cuyo contenido abarcaría mucho más que una mera declaración de principios, salvo que se entienda que nos encontramos en la excepción referida, -algo que no resulta demasiado claro-. Pero profundicemos en el tema.

\footnotetext{
${ }^{29}$ Real Decreto 945/2005, de 29 de julio de 2005.
}

${ }^{30}$ Ley Orgánica 1/2006, de 10 de abril, de reforma de la Ley Orgánica 5/1982, de 1 julio, de Estatuto de Autonomía de la Comunidad Valenciana, BOE núm. 86 de 11 de abril de 2006.

${ }^{31}$ Ley Orgánica 6/2006, de 19 de julio, de reforma del Estatuto de Autonomía para Cataluña, BOE núm. 172, de 20 de julio de 2006.

32 Ley Orgánica 2/2007, de 19 de marzo, de reforma del Estatuto de Autonomía para Andalucía, BOE núm. 68, de 20 de marzo de 2007. 
En la reforma del Estatuto de la Comunidad Valenciana (Ley Orgánica 1/2006, de 10 de abril) las competencias de esta Comunidad no han variado en gran medida, asumiendo en el marco de las normas básicas del Estado "el desarrollo legislativo y la ejecución del régimen de radiodifusión y televisión y del resto de medios de comunicación en la Comunitat Valenciana" 33 . Sin embargo, con posterioridad a la reforma del Estatuto, la Ley valenciana del sector audiovisual ${ }^{34}$ establece expresamente la titularidad de la Comunidad sobre los canales múltiples digitales destinados a la cobertura de su territorio ${ }^{35}$, lo cual en nuestra opinión no puede aceptarse jurídicamente si atendemos a la legislación vigente en el momento de aprobación de la $\mathrm{Ley}^{36}$, en especial el ERTV, que además sigue siendo aplicable en lo que afecte al tercer canal de televisión, ya sea analógico o digital. Todo ello, salvo que el término "titularidad" se use en un sentido no técnico o que, como creemos que ha pasado, la Ley audiovisual de Valencia se haya adelantado a lo proyectado en el borrador de la Ley General Audiovisual. De igual manera hay que referirse, a la asunción de la "regulación íntegra de la organización autonómica en materia audiovisual adecuando las competencias y definiendo responsabilidades" 37 , lo que en principio choca con los preceptos del ERTV y LTC que como vimos establecen los criterios de organización a los que ha de ajustarse la gestión del tercer canal de titularidad estatal (canal autonómico).

En Cataluña la reforma estatutaria ha ido mucho más allá en todos los aspectos y por supuesto en el ámbito de la comunicación. Es de destacar la asun-

${ }^{33}$ Art. 62 de la Ley Orgánica 1/2006.

${ }^{34}$ Ley 1/2006, de 19 de abril, de la Generalitat Valenciana, del sector audiovisual.

35 Art. 32 de la Ley 1/2006, de 19 de abril, del sector audiovisual de Valencia.

${ }^{36}$ Véase la d.a.44 de la Ley 66/1997, el Real Decreto 2169/1998, de 9 de octubre, por el que se aprueba el Plan Técnico Nacional de la Televisión Digital Terrenal, en la d.a.2 establece expresamente la transición digital para las concesionarias del servicio público esencial, vigente en el momento de aprobación de la Ley Audiovisual de Valencia, y el art. 2 del Real Decreto 945/2005, de 29 de julio, por el que se aprueba el Reglamento general de prestación del servicio de televisión digital terrestre y que establece: "la gestión directa del servicio se ajustará a lo establecido en la Ley 4/1980, de 10 de enero, del Estatuto de la Radio y Televisión, y en la Ley 46/1983, de 26 de diciembre, reguladora del tercer canal de televisión, y a lo que en su caso, establezca la normativa que lo sustituya".

${ }^{37}$ Art. 1.3 de la Ley 1/2006, del sector audiovisual de Valencia. 
ción de la competencia exclusiva ${ }^{38}$ en la organización de la prestación del servicio público de comunicación audiovisual de la Generalitat y de los servicios públicos de comunicación audiovisual de ámbito local, respetando la garantía de autonomía local; así como de la competencia compartida ${ }^{39}$ sobre la regulación y control de los servicios de comunicación audiovisual que utilicen cualquiera de los soportes y tecnologías disponibles dirigidas al público de Cataluña, y de la oferta de comunicación audiovisual si se distribuyen en el territorio de Cataluña. A lo que se añaden las competencias sobre las condiciones de los edificios para la instalación de infraestructuras comunes de telecomunicaciones y radiodifusión, la resolución de conflictos entre operadores de radiodifusión que compartan múltiplex de cobertura no superior al territorio de Cataluña y la designación o participación de los miembros de la Comisión del Mercado de las Telecomunicaciones y el Consejo de Radio y Televisión.

Estas medidas no son sin embargo, las primeras que se toman en Cataluña. Con anterioridad a la reforma estatutaria, la Ley de comunicación audiovisual de Cataluña ${ }^{40}$ incluye importantes reformas en el sector. Específicamente, en el ámbito de las telecomunicaciones -competencia exclusiva del estado en virtud del art. 149.1. CE-, atribuyó a la Comunidad competencias sobre planificación y gestión del espacio radioeléctrico, además de la participación en la planificación estatal sobre la base de que es un elemento instrumental de los servicios de comunicaciones. Regulando, a su vez, determinados aspectos de las telecomunicaciones en la medida en que participaban en la prestación de los servicios de comunicación audiovisual, principalmente los operadores de redes, los servicios de comunicación electrónica y los operadores de servicios de acceso condicional, regulando en este sentido determinadas obligaciones de transmisión, distribución, etc. de tales operadores.

Esta decisión por parte de la Comunidad Autónoma de Cataluña, como precisa Souvirón Morenilla, es "un tanto discutible que, no obstante, pudiera

38 que incluye de forma íntegra la potestad legislativa, reglamentaria y la función ejecutiva, según su propia tipología de competencias (Art. 110 del nuevo Estatuto de Autonomía para Cataluña).

39 integrada por la potestad legislativa, la potestad reglamentaria y la función ejecutiva, en el marco de las bases que fije el Estado como principios o mínimo común normativa en normas con rango de ley, excepto en los supuestos que se determinen de acuerdo con la Constitución y el presente Estatuto (Art. 111 del nuevo Estatuto de Autonomía para Cataluña).

${ }^{40}$ Ley 22/2005, de 29 de diciembre. 
hallar cierto fundamento en alguna jurisprudencia constitucional antecedente ${ }^{41}$ que, como criterio para la ubicación de una actividad en el artículo 149.1.21 CE (telecomunicaciones, competencia exclusiva del Estado) o en el 149.1.27 (medios audiovisuales, compartida entre el Estado y las Comunidades Autónomas), evocó el carácter predominante que en esa actividad alternativamente tuvieran los aspectos técnicos (art. 149.1.21) o los de la comunicación y los contenidos audiovisuales (art. 149.1.27), e incluso resultar coincidente con algunas de las previsiones del Anteproyecto de Ley General Audiovisual que viene preparando el Estado" 42 , y al que ahora nos vamos a referir. En este sentido el art. 69 del borrador de Ley General Audiovisual reconoce a las Comunidades Autónomas competencias para determinar la capacidad de dominio público radioeléctrico, al igual que el número y las características de las licencias que podrán hacer uso del dominio público planificado.

El nuevo Estatuto de Autonomía de Andalucía contiene una ampliación importante de las competencias asumidas en el Estatuto de 1980. Las novedades, al igual que en la reforma estatutaria de Cataluña, no se limitan a los títulos competenciales, sino que afectan a la propia clasificación o tipología de competencias, definiendo lo que ha de entenderse por competencia exclusiva, compartida y ejecutiva. Además de establecer una cláusula de cierre en virtud de la cual todo aquello que no sea atribuido expresamente al Estado es competencia autonómica. En todo caso, el nuevo Estatuto andaluz muestra una evidente voluntad de encajar sus previsiones en el marco constitucional.

En cuanto a las competencias establecidas en materia de comunicación audiovisual, muy similares a las recogidas en el Estatuto catalán, destaca: a) la competencia exclusiva sobre la organización de la prestación del servicio público de la comunicación audiovisual de la Junta de Andalucía y de los servicios públicos de comunicación audiovisual de ámbito local, respetando la garantía de la autonomía local (hasta aquí el precepto es prácticamente una copia del catalán, aunque Andalucía hace mención expresa a la competencia exclusiva para regular, crear y mantener todos los medios de comunicación social necesarios para el cumplimiento de sus fines); b) la competencia compartida sobre ordenación, regulación y control de los servicios de comunica-

\footnotetext{
41 Nota propia, véase la STC 168/1993, f.j. $4^{\circ}$.

42 SOUVIRÓN MORENILLA, J.M (2006): "La regulación de las telecomunicaciones y la Administración Local", Revista de Estudios de Administración Local y Autonómica, Madrid, INAP, en prensa.
} 
ción audiovisual que utilicen cualquiera de los soportes y tecnologías disponibles dirigidos al público de Andalucía, así como sobre las ofertas de comunicación audiovisual si se distribuyen en el territorio de Andalucía. También participará en los procesos de designación de los miembros de los órganos de dirección de la Comisión del Mercado de las Telecomunicaciones e igualmente tendrá competencia sobre las condiciones de los edificios para la instalación de infraestructuras comunes de telecomunicaciones y radiodifusión. A su vez será función del Parlamento de Andalucía, el control de los medios de comunicación social dependientes de la Comunidad Autónoma y corresponderá al Consejo Audiovisual de Andalucía velar por los principios constitucionales.

Pero junto a todo esto, el Estatuto de Andalucía incluye un título específico, el título VIII, referido exclusivamente a los medios de comunicación social. En él destaca la mención expresa a los principios que han de regir la actividad de los medios de comunicación públicos gestionados directamente por la Junta de Andalucía y las Corporaciones locales, correspondiendo al Parlamento el control de los medios de comunicación gestionados directamente por la Junta de Andalucía a través de una comisión parlamentaria. Y la posibilidad de la Comunidad Autónoma de crear nuevos canales audiovisuales u otros medios de comunicación en el marco del ordenamiento jurídico la propuesta de reforma.

En definitiva y de todo lo expuesto, merece especial atención la posibilidad que abren los Estatutos de Autonomía de que las Comunidades Autónomas tengan canales de titularidad propia ${ }^{43}$. Titularidad que aunque no se menciona expresamente en los Estatutos valenciano y catalán, se encuentra latente en la reciente regulación audiovisual, de las propias Comunidades Autónomas (la Ley 1/2006, de 19 de abril, de la Generalitat Valenciana, o la Ley 22/2005, de 29 de diciembre, de la comunicación audiovisual de Cataluña).

Digamos en todo caso, que los nuevos Estatutos rompen con la autolimitación en materia de medios audiovisuales establecida por los Estatutos originarios, y que por ello en tanto no se apruebe la nueva Ley General Audiovisual y se derogue completamente el ERTV estaremos ante una situación normativa no exenta de confusión, que podría extenderse incluso tras la aproba-

${ }^{43}$ posibilidad contradictoria con lo dispuesto por el ERTV de 1980, ya hemos dicho no derogado en lo que afecta a la televisión de ámbito autonómico. 
ción de la Ley General Audiovisual, dado el nuevo carácter de principios que los nuevos Estatutos otorgan a la normativa estatal básica. Confusión que quizá exija que de acuerdo con el art. 28 de la Ley Orgánica del Tribunal Constitucional, éste reinterprete el esquema competencial o en su caso declare la inconstitucionalidad de los preceptos estatutarios.

\section{CONCLUSIONES}

1) La regulación de los medios de comunicación audiovisuales se ha caracterizado históricamente por la centralización y monopolio estatal.

2) Las Comunidades Autónomas, en principio con posibilidad de tener competencias en la materia audiovisual de acuerdo al desglose constitucional bases-desarrollo se autolimitaron al someterse a la legislación estatal que regulase la materia y a la concesión de un tercer canal de titularidad estatal.

3) El avance tecnológico ha provocado un desarrollo en el ámbito audiovisual quedando regulado de manera sectorial en función de la técnica utilizada para la difusión de los mensajes comunicativos.

4) La descentralización de los medios de comunicación audiovisuales ha seguido una evolución progresiva conforme al desarrollo de la técnica y la evolución del Estado de las Autonomías.

5) La necesidad de un conjunto normativo sintético y ordenado ha originado un plan de reforma coherente con el sistema constitucional pero cuya aprobación parcial no deja una situación satisfactoria.

6) Las reformas de los Estatutos de Autonomía en el último año han ampliado la asunción de competencias autonómicas especialmente conforme a los nuevos medios de comunicación que puedan crearse.

7) La liberalización y descentralización estatal de los medios de comunicación audiovisuales choca con una progresiva centralización autonómica. 